\title{
Bariatrik Cerrahi Olgularında Preoperatif Değerlendirme Sırasında Tespit Edilen Hastalıkların Prevalansı
}

\section{Prevalence of the Diseases Detected During Preoperative Evaluation in Bariatric Surgery Cases}

\author{
Feyzi Gökosmanoğlu ${ }^{1}$, Kerim Güzel², Gülşah Bayçelebi ${ }^{3}$ \\ ${ }^{1}$ Medicana İnternational Samsun Hastanesi, Endokrinoloji Kliniği, Samsun \\ ${ }^{2}$ Medicana İnternational Samsun Hastanesi, Genel Cerrahi Kliniği, Samsun \\ ${ }^{3}$ Atasam Hastanesi, İç Hastalıkları Kliniği, Samsun \\ Yazışma Adresi / Correspondence: \\ Feyzi Gökosmanoğlu \\ Yenimahalle, Sht. Mesut Birinci Cd. No:85, 55080 Canik/Samsun \\ $\mathrm{T}:+903623110505 \quad$ E-mail : gokosmanogluu@gmail.com \\ Geliş Tarihi / Received : 08.09.2020 Kabul Tarihi / Accepted : 13.10.2020 \\ Orcid : \\ Feyzi Gökosmanoğlu https://orcid.org/0000-0002-6432-8668 \\ Kerim Güzel https://orcid.org/0000-0003-3882-311X \\ Gülșah Bayçelebi https://orcid.org/0000-0001-9375-786X \\ ( Sakarya Tip Dergisi / Sakarya Med J 2020, 10(4):650-654) DOI: 10.31832 smj.791837
}

Öz

Amaç Obezite prevalansı dünya çapında artmaktadır. Bu durum önemli bir sağlık sorunudur. Morbid obezite de başarılı tedavi yöntemlerinden biride bariatrik cerrahidir. Obeziteye eșlik eden hastalıkların tesbit edilmesi, preoperatif mortalite riskini ve postoperatif başarıyı öngörmemizi sağlayacaktır.

Gereç ve Araștırmamız Ekim 2016-Ağustos 2020 ylları arasında hastanemiz metabolik ve bariatrik cerrahi kliniğimizde morbid obezite nedeni ile bariatrik cerrahi yapılan toplam Yöntem 742 olgu üzerinde yürütüldü.

Bulgular Dosyaları incelenen 742 hastanın kayıtları değerlendirildi. Hastaların 474 kadın, 268 erkek, yaş ortalaması $50.8 \pm 8.9$ yıl, ortalama vücut kitle indeksi (VKI) $48.9 \pm 5.0$ kg/ $\mathrm{m} 2$ idi. Obezite prevalansındaki artış ile tip-2 diyabet, hipertansiyon, metabolik sendrom ve diğer hastalıklarda ciddi artışlar tesbit edildi. Tiroid ve adrenal bez hastalıkları prevalansında artış sıklı̆̆ı göze çarpmaktadır.

Sonuç Obezite prevalansındaki artıș ile birlikte obeziteye eșlik eden hastalıklarda da artış saptanmaktadır. Obezite olguları preoperatif dönemde değerlendirilmeleri sırasında eșlik eden hastalıkların saptanması, cerrahi öncesi bu hastalıkların tedavisi, cerrahiye bağlı mortalite ve morbiditeyi azaltır, cerrahinin bașarısını artırır.

Anahtar Bariatrik cerrahi; preoperatif değerlendirme; obezite

Kelimeler

Abstract

Objective The prevalence of obesity is increasing worldwide. This has become an important health problem. One of the successful treatment methods in morbid obesity is the bariatric surgery. Detecting the diseases that accompany obesity will enable us to predict the risk of preoperative mortality and postoperative success.

Materials The present study was conducted between October 2016 and August 2020 on a total of 742 cases that underwent bariatric surgery because of morbid obesity in our hospital metabolic and and methods bariatric surgery clinic.

Results The records of a total of 742 patients whose medical files were examined were evaluated in the study. The mean age of 474 women, 268 men was $50.8 \pm 8.9$ years, the mean body mass index (BMI) was $48.9 \pm 5.0 \mathrm{~kg} / \mathrm{m} 2$. Significant increases were detected with the increase in obesity prevalence and Type-2 Diabetes, Hypertension, Metabolic Syndrome and other diseases. There is an increase in the prevalence of thyroid and adrenal gland diseases.

Conclusion An increase was detected in the diseases that accompany obesity with the increase in obesity prevalence. Obesity decreases the detection of comorbidities during the evaluation of cases in preoperative period, pre-surgical treatment, and reduces mortality and morbidity because of surgery, and increases the success of surgery.

Keywords Bariatric surgery; preoperative evaluation; obesity 


\section{GIIRIŞ}

Obezite prevalansı yetişkinlerde, ergenler ve çocuklar arasında dünya çapında çok ciddi artmaktadır. Bu durum dünyada önemli bir sağlık sorunu haline geldi. ${ }^{1}$ Ergenlik dönemindeki yağ birikimi, yetişkinlerde ateroskleroz ve birçok hastalık ile direk ilişkilidir. ${ }^{2}$ Bariatrik cerrahi, diyabet ve kardiyovasküler hastalıklar gibi obezite ile ilişkili komorbiditelerde ve obeziteye bağlı mortalitede en etkili obezitenin kalıcı tedavisidir. ${ }^{3-4}$ Morbid obezite hastalarında uzun vadeli en başarılı tedavi yöntemi bariatrik cerrahidir. Bu ameliyat önemli morbidite ve potansiyel mortalite riskleri taşır. Bariatrik cerrahide obeziteye eşlik eden hastalıkların preoperatif dönemde tanımlanması hakkında yayınlanmış makale çok azdır. ${ }^{5}$

Bir hastanın vücut kitle indeksi arttıkça, cerrahi komplikasyon geliştirme riski de artar. $^{6}$ Obezitede hiperkapni ve uyku apnesi, obezite ile ilişkili aterosklerotik kardiyovasküler hastalık, kalp yetmezliği, sistemik ve pulmoner hipertansiyon, kardiyak aritmiler, derin ven trombozu ve pulmoner emboli görülme riskinin arttığı bilinmektedir.? Obez hastaların operasyona güvenli bir şekilde hazırlanması için multidisipliner yaklaşılmalıdır. Bu hastalarda perioperatif değerlendirme çok önemlidir. ${ }^{8}$ Obezite ile ilişkili hastalıklar bariatrik cerrahiden önce tespit edilmelidir. $\mathrm{Bu}$ çalışmanın amacı bariatrik cerrahi öncesi hastaların yönetiminde multidisipliner değerlendirme ile obeziteye eşlik eden ya da obeziteye neden olan hastalıkların tespit edilmesi, bu tespitlerin bize preoperatif mortalite riskini ve postoperatif başarıyı öngörmemizi sağlayacağını düşünüyoruz.

\section{GEREÇ ve YÖNTEMLER}

Araştırmamız Ekim 2016-Ağustos 2020 yılları arasında hastanemiz metabolik ve bariatrik cerrahi kliniğimizde (Medical Park Ordu Hastanesi, Medicana İnternational Samsun Hastanesi) morbid obezite nedeni ile bariatrik cerrahi yapılan toplam 742 olgu üzerinde yürütüldü. Her bir olgunun değerlendirilmesi dosya ve elektronik kayıtlarından geriye yönelik olarak antropometrik, fizik mu- ayene ve laboratuvar verilerine ulaşıldı ve kaydedildi. $\mathrm{Bu}$ araştırma hastaların verileri retrospektif olarak dosyaları ve elektronik kayıtları incelenerek yapılan kesitsel tipte tanımlayıcı bir çalışmadır. Çalışmamız Medicana İnternational Samsun Hastanesi klinik araştırmalar etik kurulu onayı (11.08.2020-1) ile, etik kurallara bağlı olarak yapıldı. Çalışma grubunu VKİ $\geq 40 \mathrm{~kg} / \mathrm{m} 2$ olan olguların bariatrik cerrahi öncesi multidisipliner yaklaşımla değerlerlendirilmesi sırasında tespit edilen hastalıkların sıklığı veri olarak kullanıldı. Çalışmaya 18-65 yaş arasındaki olgular alındı. Hastanemizde multidisipliner çalışma grubunu endokrinoloji, genel cerrahi, iç hastalıkları, göğüs hastalıkları, psikiyatri ve psikolog, kardiyoloji, diyetisyen, anestezi uzmanları tarafından oluşturulmaktadır. Hastalar bu ekip tarafından ayrı ayrı değerlendirilmiştir. $\mathrm{Bu}$ çalışmanın amaçları doğrultusunda, başlangıçta yeterli değerlendirmede bulunulmayan olgular çalışma dışı bırakıldı.

Veri analizi SPSS (Statistical Package for the Social Sciences) 22,0 istatistik paket programı kullanılarak yapıldı. Değişkenler ortalama \pm standart sapma değerleri ya da yüzde olarak ifade edildi. Sürekli değişkenlerin normal dağılım gösterip göstermediği Shapiro Wilks testi ile incelendi. Bağımsız iki grup karşılaştırmasında t-testi kullanıldı. İkili grup karşılaştırmalarında normal dağılıma uygun olmayanlar için Mann-Whitney U testi kullanıldı. İstatistiksel anlamlılık düzeyi $\mathrm{p}<0.05$ olarak belirlendi.

\section{BULGULAR}

Dosyaları incelenen 742 hastanın kayıtları değerlendirilmeye alındı. Hastaların 474 (\%63.8) kadın, 268 (\%36.1) erkek, yaş ortalaması $50.8 \pm 8.9$ yıl, ortalama VKİ $48.9 \pm 5.0$ $\mathrm{kg} / \mathrm{m} 2$ idi. Çalışma grubunun sosyo demografik özellikleri tablo 1'de görülmektedir. 


\begin{tabular}{|l|c|}
\hline \multicolumn{2}{|l|}{ Tablo 1.Hastaların sosyodemografik özellikleri } \\
\hline Parametreler & $\mathrm{n}: 742$ \\
\hline Yaş (ort \pm SD) & $50,8 \pm 8,9$ \\
\hline Cinsiyet & $474(\% 63,8)$ \\
\hline Kadın, n (\%) & $268(\% 36,1)$ \\
\hline Erkek, n (\%) & $118,1 \pm 8,3$ \\
\hline Kilo, kg & $48,9 \pm 5,0$ \\
\hline VKİ, kg/m2 & VKİ; Vücut kitle indeksi, ort; ortalama, SD; standart deviasyon \\
\hline
\end{tabular}

Obezite hastalarında tip-2 diyabet 89 (\%11.9),hipertansiyon 231 (\%31.1), metabolik sendrom 489 (\%65)'unda tesbit edildi. Buna karşılık daha önce tanı alan olgulardan tip-2 diyabet 178 (\%23.9), hipertansiyon 225 (\%30.3)'unda vardı. İlk defa bu çalışmada obezite hastalarda bariatrik cerrahi öncesi nodüler guatr, tiroid kanseri, adrenal adenom, mide kanseri prevalansı saptand. Olgularda palpe edilebilir nodül sıklığı \%3.3 $(n=25)$ ve ultrasonogarfide saptanabilir tiroid nodülü prevalansı \%47.2 (n=311) oranında bulundu. Hastalarından 658 kişiye tiroid ultrasonografi yapılmış. Nodül saptanan 514 olguya ince iğne biyopsi yapıldığ 1 tesbit edildi. Tiroid malignite prevalansı \% $11.8(n=61)$ olarak saptandı. Olgulardan 623 kişiye üst batın tomografi çekilmiş. Adrenal adenom prevalansı \%8.1 $(\mathrm{n}=51)$ olarak saptand, subklinik cushing 16 (\%2.1), cushing sendromu 5 kişide, feokromasitoma 2 kişide saptand. Mide kanseri ise 5 olguda saptandı. Obeziteye eşlik eden en sık hastalık metabolik sendromdur. Ayrıca dislipidemi, hipertansiyon ve koroner kalp hastalığı prevalansının obezite ile birlikte arttı̆̆1, yine preoperatif değerlendirme sırasında tespit edilen hastalıklar tablo 2'de görülmektedir.

\section{TARTIŞMA}

Obezite prevelansının artması beraberinde obeziteye bağlı hastalıkların da sıklığının artmasına neden olmaktadır. Obezite ile birlikte metabolik-hormonal hastalıklar, hipertansiyon ve kalp hastalığ riski artmaktadır. ${ }^{9-10}$ Obez hastalarda metabolik sendrom, hipertansiyon, dislipidemi, tip 2 diyabet ve aterosklerotik kardiyovasküler hastalık gelişimi sıklığı dünyada ve ülkemizde artmıştır. Özellikle oluştudu- ğu vasküler hastalıklar nedeni ile morbidite ve mortalitede obezitenin önemli etkileri vardır. ${ }^{10-11}$ Araştırmamızda obezite prevalansı artışı ile metabolik-hormonal hastalıklar, kardiyovasküler hastalıkların prevalansında ciddi artış ile birlikte olduğu tablo 2'dedir.

Tablo 2. Bariatrik cerrahi operasyonuna hazırlık sırasında obez olguların değerlendirilmeleri sırasında tespit edilen hastalıkların sıklığı

\begin{tabular}{|c|c|}
\hline Parametreler & $\begin{array}{l}\text { Hastalıkların } \\
\text { sıklığı, n(\%) }\end{array}$ \\
\hline $\begin{array}{l}\text { Metabolik-hormonal hastalıklar } \\
\text {-Metabolik sendrom } \\
\text { - Tip } 2 \text { diyabet } \\
\text { - Dislipidemi } \\
\text { - Hipertansiyon }\end{array}$ & $\begin{array}{l}480(\% 64.6) \\
267(\% 35,9) \\
310(\% 41,7) \\
456(\% 61,4)\end{array}$ \\
\hline Ateroskleroz+koroner arter hastalığ 1 & $81(\% 10,9)$ \\
\hline Uyku Apne+Obstruktif Uyku Apnesi & $356(\% 47,9)$ \\
\hline $\begin{array}{l}\text { Tiroid hastalıkları } \\
\text { • Hipotiroidi ve subklinikhipotiroidi } \\
\text { - Hipertiroidi ve subklinikhipertiroidi } \\
\text { • Nodüler guatr }\end{array}$ & $\begin{array}{c}59(\% 7,9) \\
31(\% 4,1) \\
311(\% 47,2)\end{array}$ \\
\hline $\begin{array}{l}\text { Gastrointestinal problemler } \\
\text { - Safra kesesi hastalığı } \\
\text { • Non-alkolik yağlı karaciğer hastalığı } \\
\text { - Gastroözofajiyalreflü hastalığı }\end{array}$ & $\begin{array}{l}237(\% 31,9) \\
455(\% 61,3) \\
178(\% 23,9)\end{array}$ \\
\hline $\begin{array}{l}\text { Kanser } \\
\text { •Mide Kanseri } \\
\text { •Tiroid kanseri }\end{array}$ & $\begin{array}{c}5(\% 0.67) \\
61(\% 11,8) \\
\end{array}$ \\
\hline Depresyon ve diğer Psikolojik Bozukluklar & $430(\% 57,9)$ \\
\hline $\begin{array}{l}\text { Adrenal bez hastalıkları } \\
\text { - Non-fonksiyonel adrenal adenom } \\
\text {-Cushing ve Subklinik Cushing sendromu }\end{array}$ & $\begin{array}{l}51(\% 8,1) \\
21(\% 2,8)\end{array}$ \\
\hline Diğer hastalıklar & $112(\% 15,0)$ \\
\hline
\end{tabular}

Obez olan kişilerde uyku apne ve obezite hipoventilasyon sendromu sıklıkla görülmektedir. Nedeni üst havayolundaki yumuşak dokunun artması ve uyku sırasında üst havayolunda kollaps olmasıdır. ${ }^{12}$ Metabolik sendromu olan olgularda orta ila şiddetli obstrüktif uyku apne (OSA) prevalansı çok yüksektir ( \%60). ${ }^{13-14}$ Çalışmamızda uyku apnea ve OSA prevalansı literatür verilerinden düşük saptanmış olup, bunun preoperatif değerlendirmenin yetersizliğinden kaynaklandığını düşünüyoruz. Reflü hastalığı \%18.1 - \%27.8, safra taşı sıklığı \%35 yine yağlı karaciğer ve non-alkolik steotohepatit sıklığ1 \%62,4--\%80 obezite 
ile birlikte görülmektedir.15-16-17Araştırmamızda gastrointestinal problemlerin literatürlerle uyumlu olduğunu saptadik.

Klinik açıdan bakıldığında, obezite ve subklinik tiroid hormon yetmezliği yaygın hastalıklardır ve sıklıkla bir arada bulunur. ${ }^{18}$ Obezitede hipotiroidi ve subklinik hipotiroidi $\% 11$, hipertiroidi \%0.8--\%2.1, nodüler guatr \%67 oranında olduğu çalışmalarda gösterilmiş. ${ }^{19-20-21}$ Araştırmalarda obezite olgularında VKİ ile tiroid hastalıkları arasında paralellik olmadı̆̆ 1 gösterilmiş. ${ }^{22}$ Subklinik hipotiroidi prevalansı yüksek olsa aslında bunun tiroid fonksiyon bozukluğu olmadığı, insülin direnci benzeri bir mekanizma üzerinden tiroid sitümülan hormon (TSH) yüksekliği olduğu gösterilmiş. ${ }^{23}$ Bizim araştırmamızda obez olgularda tiroid hastalıkları prevalansı hipotiroidi ve subklinik hipotiroidi $\% 7.9$, hipertiroidi $\% 4.1$, nodüler guatr \%47.2 saptadik.

Klinik araştırmalarda obez olgularda depresyon ve diğger psikolojik bozuklukların prevalasının arttığı gösterilmiş. ${ }^{24}$ Olgularda anksiyete, depresyon, kendinden memnuniyetsizlik oranında artışa dikkat çekilmiş. Araştırmalarda depresyon ve diğer psikolojik bozukluklar \%45.2-50 oranında saptanmış. ${ }^{25-26}$ Biz çalışmamızda depresyon ve diğer psikolojik bozukluklar sıklığını \%57.9 oranında saptadık.

Çalışmalarda adrenal adenom \%1-2, subklinik cushing sendromu pravalansı $\% 9$ oranında tesbit edilmiş. ${ }^{27}$ Başka çalışmalarda adrenal insidentaloma sıklığı \%3, yaşlılarda $\% 10$ olarak saptanmış. ${ }^{28}$ Bizim araştırmamızda adrenal adenom \%8.1, cushing ve subklinik cushing sendromunu $\% 2.8$ oranında saptadık. Ayrıca mide kanserini \%0.67, tiroid kanseri \%11.8 saptadık. Araştırmalarda obezitenin mide ve tiroid kanseri riskini artırdığı gösterilmiş. ${ }^{29-30} \mathrm{Bi}$ zim araştırmamızda hem mide hemde tiroid kanserinin obez olgularda çok ciddi arttığını saptadık.

Sonuç olarak seçilmiş vakalarda obezite tedavisi için bariatrik cerrahi iyi bir yöntemdir. Obez hastalar preoperatif dönemde multidisipliner bir grup tarafından detaylı değerlendirilmelidir. Obezite ile birlikteliği olan hastalıklar tesbit edilmelidir. Bu tür klinik yaklaşım operatif komplikasyonları,mortalite ve morbidite riskini azaltır. Böylece bariatrik cerrahinin kontrendike olduğu olgular operasyon öncesi saptanmış olur.

\section{Çalışmanın kısıtlılıkları}

Bu çalışmanın bazı kısıtlılıkları mevcuttur. Çalışma retrospektif dizayn edilmiş olup prospektif çalışmalarla desteklenmelidir. Ayrıca çalışma retrospektif olarak yapıldığ için hastaların özgeçmişleri ve diğer komorbid hastalıkları ayrıntılı olarak değerlendirilememiştir.

\section{Etik Onam}

Medicana İnternational Samsun Hastanesi klinik araştırmalar etik kurulu onayı (11.08.2020-1) ile, etik kurallara bağlı olarak yapıldı. 
Sakarya Tıp Dergisi 2020;10(4):650-654

GÖKOSMANOĞLU ve Ark., Bariatrik Cerrahi ve Preoperatif Değerlendirme

\section{Kaynaklar}

1. Aguilera C, Labbé T, Busquets J, Venegas P, Neira C, Valenzuela A. Obesity: risk factor or primary disease?.Rev Med Chil 2019;147(4):470-474.

2. Engin A. The Definition and Prevalence of Obesity and Metabolic Syndrome. Adv Exp Med Biol 2017;960:1-17.

3. Lee CJ, Clark JM, Asamoah V, Schweitzer M, Magnuson T, Lazo M. Prevalence and characteristics of individual swith out diabetes and hypertension who under went bariatric surgery:lessons learned about metabolic ally healthy obese. Surg Obes Relat Dis 2015;11(1):142146.

4. Buchwald H, Estok R, Fahrbach K, Banel D, Jensen MD, Pories WJ. Weight and type 2 diabetes after bariatric surgery: systematic reviewand meta-analysis.Am J Med 2009; 122(3):248-256.

5. Thomas H, Agrawal S. Systematic review of obesity surgery mortality risk score preoperative risk stratification in bariatric surgery. Obes Surg 2012;22(7):1135-40.

6. Ferrada P, Anand RJ, Malhotra A, Aboutanos M. Obesity Does Not Increase Mortality after Emergency Surgery. Journal of Obesity 2014:1-3.

7. Bell T, Stokes S, Jenkins PC, Hatcher L, Fecher AM. Prevalence of cardiovascular and respiratory complications following trauma in patient swith obesity. Heart Lung 2017;46(5):347350.

8. Ortiz VE, Kwo J. Obesity: physiologic changes and implications for preoperative management. BMC Anesthesiol 2015;4;15:97.

9. George A. Bray, Medical Consequences of Obesity, The Journal of Clinical Endocrinology e Metabolism 2004;2583-2589.

10. Mc Donald A, Bradshaw RA, Fontes F. Prevalence of obesity in panama: some risk factors and associated diseases. BMC Public Health 2015;15:1075.

11. Cinza Sanjurjo S, Prieto Díaz MÁ, Llisterri Caro JL. Prevalencia de obesidady comorbilidad cardiovascular asociada en lospacientes incluidos en el estudio IBERICAN (Identificación de la poBlación Española de RIesgo CArdiovascular y reNal) [Prevalence of obesity and cardiovascular comorbidity associated in patients included in the IBERICAN study]. Semergen 2019;45(5):311-322.

12. Balkan F. Metabolik Sendrom. Ankara Medical Journal 2013;13:2.

13. Drager LF, Togeiro SM, Polotsky VY, Lorenzi-Filho G. Obstructive sleep apnea: a cardiometabolic risk in obesity and the metabolic syndrome. J Am Coll Cardiol 2013;62(7):569-576.

14. Jordan AS, McSharry DG, Malhotra A. Adult obstructive sleep apnoea. Lancet 2014;383(9918):736-747.

15. Grewal G, Joshi GP. Obesity and Obstructive Sleep Apnea in the Ambulatory Patient. Anesthesiol Clin 2019;37(2):215-224
16. Chang P, Friedenberg F. Obesity and GERD. Gastroenterol Clin North Am 2014;43(1):161173.

17. Khatua B, El-Kurdi B, Singh VP. Obesity and pancreatitis. Curr Opin Gastroenterol 2017;33(5):374-382

18. Milić S, Lulić D, Śtimac D. Non-alcoholic fatty liver disease and obesity: biochemical, metabolic and clinical presentations. World J Gastroenterol 2014;20(28):9330-9337.

19. Verma A, Jayaraman M, Kumar HK,Modi KD. Saudi Med J 2008;29(8):1135-8.

20. Sanyal D, Ray chaudhuri M. Hypothyroidism and obesity: An intriguinglink. Indian J Endocrinol Metab 2016;20(4):554-557.

21. Ríos-Prego M, Anibarro L, Sánchez-Sobrino P. Relationship between thyroid dysfunction and body weight: a not so evident paradigm. Int J Gen Med 2019;12:299-304.

22. Sousa PA, Vaisman M, Carneiro JR. Prevalence of goiter and thyroid nodular disease in patient swith class III obesity. Arq Bras Endocrinol Metabol 2013;57(2):120-125.

23. Gokosmanoglu F, Aksoy E, Onmez A, Ergenç H, Topkaya S. Thyroid Homeostasis After Bariatric Surgery in Obese Cases. Obes Surg 2020;30(1):274-278.

24. Ayloo S, Thompson K, Choudhury N, Sheriffdeen R. Correlation betweenthe Beck Depression Inventory and bariatric surgical procedures. Surg Obes Relat Dis 2015;11(3):637-642.

25. Alabi F, Guilbert L, Villalobos G. Depression Before and After Bariatric Surgery in Low-Income Patients: the Utility of the Beck Depression Inventory. Obes Surg 2018;28(11):3492 3498 .

26. Petri E, Bacci O, Barbuti M. Obesity in patients with major depression is related to bipolarity and mixed features: evidence from the BRIDGE-II-Mix study. Bipolar Disord 2017;19(6):458-464.

27. Reincke M, Beuschlein F, Bornstein S. The Adrenal Gland: Central Relay in Health and Disease. Exp Clin Endocrinol Diabetes 2019;127(2-03):81-83.

28. Unger N. Inzidentalome der Nebennieren :Diagnostis chesund therapeutis ches Konzeptaus endokrinologischer Sicht [Adrenal incidentaloma : Diagnostic and therapeutic concept from an endocrinological perspective] [published correction appears in Chirurg 2019Feb 8::]. Chirurg 2019;90(1):3-8.

29. Chen Y, Liu L, Wang X, Wang J, Yan Z, Cheng J. Body mass index and risk of gastric cancer: a meta-analysis of a population with more than ten million from 24 prospective studies. Cancer Epidemiol Biomarkers Prev 2013;22(8):1395-40.

30. Kushchayeva YS, Kushchayev SV, Startzell M. Thyroid Abnormalities in Patients With Extreme Insulin Resistance Syndromes. J Clin Endocrinol Metab 2019;104(6):2216-2228. 